\title{
Isabel Barca: caminhos trilhados pela Educação Histórica
}

\section{Nucia Alexandra Silva de Oliveira ${ }^{1}$}

Meu encontro com Isabel Barca² para a realização desta entrevista aconteceu numa fria e bela manhã de inverno na cidade de Curitiba/PR. Entre os tantos compromissos que se somava por conta da realização do XII Jornadas de Educação Histórica, Isabel cedeu generosamente parte de seu tempo para essa nossa conversa sobre sua trajetória como professora e pesquisadora e sobre suas pesquisas atuais. Conversamos e gravamos seu depoimento em uma das salas do prédio Pedro II na Universidade Federal do Paraná e durante esse tempo pude perceber em sua simpática narrativa a paixão de uma professora por seu trabalho!

Como se sabe, Isabel Barca é uma das principais referências no campo da Educação Histórica tanto em seu país de origem quanto aqui no Brasil e assim parece bastante apropriado saber como ela tomou conhecimento desta área, como optou por estudá-la e que caminhos foram trilhados para consolidar a área em Portugal. Lendo o seu relato será possível perceber que foram a sensibilidade e o interesse de uma professora atenta e preocupada que a levaram a buscar outros caminhos para o ensino de história. E de acordo com ela, a vontade de entender como os/as alunos/as aprendem história foi o grande motor de sua busca.

Como será possível ler nas páginas a seguir, Isabel teve e tem um papel extremamente importante para a Educação Histórica em Portugal, pois além de percursora foi uma das pessoas que atuou junto a Associação de Professores de História no sentido de levar a um grupo maior de pessoas as possibilidades colocadas pela área. Este movimento que incorpora professores em formação continuada e em cursos de pós

\footnotetext{
${ }^{1}$ Mestre e Doutora em História pela Universidade Federal de Santa Catarina (UFSC). Professora adjunta no curso de História da Universidade do Estado de Santa Catarina (UDESC)

${ }^{2}$ Isabel Barca é professora na Universidade do Minho.
} 
e de graduação tem alcançado grande sucesso. Além disso, merece também destaque sua atuação junto às estruturas políticas que repercutiram na inserção das perspectivas relacionadas à Educação Histórica nas políticas de ensino em Portugal.

A presente entrevista permite, portanto, que tenhamos conhecimento dessa rica trajetória e que novamente sejam lembrados aspectos importantes apontados por Barca em seus trabalhos. Chamo atenção para sua ênfase sobre a relevância da narrativa para o aprendizado histórico; afinal, como ela salienta, narrar é uma forma de comunicar ideias. Destaco também seus apontamentos sobre as formas de trabalhar com as ideias substantivas.

Vale dizer que esta entrevista também aborda o trabalho de Barca como formadora de professores. Destaca-se em sua fala a busca por promover o entusiasmo entre os professores mostrando a eles como é importante buscar em suas atividades um envolvimento que pode ser feito, por exemplo, através de atividades investigativas. De acordo com ela, tanto professores quanto alunos sentem-se mais motivados quando se percebem parte do processo de ensino. Algo certamente muito pertinente!

Como disse no início desta apresentação esse encontro com Isabel Barca teve como objetivo buscar conhecer um pouco mais sobre sua trajetória, sobretudo considerando a potencialidade de sua obra e o fato de suas ideias serem amplamente usadas por aqueles que optam pelos pressupostos da Educação História. Nesse sentido a leitura deste texto convida ao conhecimento da obra desta pesquisadora, mas também se coloca como uma proposta para novos diálogos sobre questões tão caras à Isabel Barca como a importância de ensinar história em função da construção de narrativas por parte dos estudantes. Em suas considerações finais nesta entrevista ela diz que atualmente está buscando sensibilizar os professores que frequentam seus cursos a pensar sobre o conceito de mudança. Uma discussão que tem potencialidade para todos - em especial para pensarmos sobre a história e sobre o mundo do qual fazemos parte contemporaneamente. Espero que as perguntas e respostas que se seguem possam auxiliar os leitores de Isabel Barca a conhecerem ainda mais as propostas desta pesquisadora e que outros diálogos sobre Educação Histórica possam acontecer...

Nucia Oliveira: Professora Isabel Barca, por favor, conte-nos um pouco sobre a sua formação e sobre a sua atuação profissional.

Isabel Barca: Eu iniciei o meu trabalho como professora e estava fazendo minha formação universitária ainda no tempo da ditadura em Portugal. E, como não tinha intenção de ser professora porque sabia que como professora teria pouca liberdade de pensar e de ensinar, nessa altura estava - paralelamente - fazendo um curso de bibliotecária e essa seria a minha orientação. Entretanto fizemos a revolução 
democrática, o problema da falta de liberdade de expressão terminou e eu, que gostava de fato da atividade de ensinar, resolvi ficar no ensino e recusei uma proposta para ficar a frente da biblioteca municipal do Porto, que era onde eu vivia. Era uma boa proposta, mas eu já estava demasiado apaixonada pelo ensino e pela possibilidade de dialogar abertamente com os meus alunos sobre as situações do passado relacionadas com o presente, e por aí fiquei.

Houve sempre de minha parte - e eu às vezes reflito sobre isso - uma vontade de entender melhor aqueles que estavam comigo em sala de aula, e, portanto uma das minhas questões pessoais era entender os alunos que vinham de outros estratos sociais que não o meu e que eu não entendia tão bem. Por exemplo, os alunos que vinham de zonas rurais quase não falavam nas aulas, os alunos que vinham de zonas de pescadores eram extremamente turbulentos e parecia não gostar da escola, mas, por alguns indicadores pontuais, mostravam que também gostavam... E por isso eu queria investigar os alunos desde que comecei a trabalhar com esses diferentes contextos.

Quando surgiu - já na década de 80 - o anúncio de um primeiro mestrado em educação para professores em Portugal - para serem futuros formadores de professores- eu apresentei minha candidatura e fui selecionada. Este Mestrado foi nos Estados Unidos, na Universidade de Boston. Portugal vindo da ditadura não tinha - no plano das Ciências Sociais - um trabalho muito avançado e também no plano da educação era complicado. Na educação em ciências que pensam sobre o ser humano houve uma censura muito grande e, portanto, havia também uma falha grande nas universidades. Para se desenvolver essas dimensões da educação em Portugal, foi necessário formar formadores de professores em outros países. Por isso, o meu mestrado foi em Ensino das Ciências Sociais na Universidade de Boston. Lá eu tive contato com experiências muito interessantes, nomeadamente com propostas de ensino ativo-ensino que nós hoje podemos considerar mais significativo para os alunos e que os mobilizava. Essas propostas iam ao encontro das minhas expectativas, das minhas ideias e daquilo que eu já tinha lido da escola francesa sobre o ensino da história com documentos, e também da Suíça como as propostas de Freinet, no sentido de educar pelo trabalho. Portanto, obtive na Universidade de Boston um conjunto de ideias que aprofundaram essas minhas indagações de trabalhar com os alunos, colocar os alunos a trabalhar de fato e eu a acompanhá-los, e de tentar percebê-los melhor. Assim, a minha tese de mestrado, de caráter sociológico ou socioantropológico, tinha precisamente a ver com perceber as atitudes dos alunos de diferentes contextos culturais em relação à escola - e, para o estudo, escolhi então esses três estratos culturais com os quais eu trabalhava: alunos de contextos pesqueiros, alunos de contextos rurais e alunos de contextos urbanos. Nessa altura, estava muita em uso uma metodologia de caráter quantitativo e, portanto eu fiz um estudo de caráter quantitativo; mas os resultados não 
me satisfizeram na medida em que não me deram respostas suficientes para as minhas indagações. Nos estudos quantitativos nós é que fazemos as perguntas e os alunos têm quase só que colocar a escolha entre as ideias que os pesquisadores têm e, portanto, isso não me satisfez. Foi por essa altura que eu passei a ser professora da Universidade, ainda no âmbito alargado das ciências sociais; claro que como tinha uma especial preferência pela história, trabalhei a história com as propostas que fui recolhendo das minhas leituras e também com o contato com as referências norte-americanas.

Entretanto chegou o momento de pensar no que fazer a seguir, eu estava interessada em avançar para o Doutorado e, como nessa altura, eu mudei de universidade e passei a trabalhar especificamente sobre o ensino de história, isso foi muito bom para mim. Eu procurei no âmbito das universidades que eu conhecia uma onde o trabalho sobre ensino de história - e já se chamava Educação Histórica estivesse mais avançado e, sem dúvida, eu percebi que era na Universidade de Londres. Aí havia um grupo de pesquisadores com um trabalho que tinha não só iluminado a prática dos investigadores, mas também iluminado a prática dos "práticos" , pois essas ideias tinham passado para as escolas. Portanto, eu entrei em contato com a Universidade de Londres e com o diretor do Departamento de Educação Histórica (Alaric Dinkinson), a partir daí inscrevi-me e foi lá que eu fiz o doutorado e encontrei a luz que eu procurava. Eu trabalhei novamente as ideias dos alunos, neste caso de adolescentes, sobre a questão da provisoriedade da explicação histórica, pois as minhas preocupações de então eram, além de querer saber mais sobre o pensamento dos alunos, explorarem também a questão de que a história não é uma história única, isto é, a questão das várias perspectivas.

Quando voltei a Portugal resolvi fazer o meu caminho com base nas experiências acadêmicas que tinha obtido, mas tentando refletir sobre os contextos em que eu iria atuar. Eu não me limitei a copiar o que se fazia na Inglaterra, mas tentei adaptar aos contextos concretos em que eu vivia e em que trabalhava, e que no plano epistemológico vinham de ideias muito ligadas à escola estruturalista - que eu tinha que desconstruir de certa forma. Além disso, tinha que desafiar os alunos e professores em formação contínua a procurar saber o que os alunos pensam... A partir daí este trabalho ganhou bastante fôlego e podemos dizer que tem sido um caso de sucesso na minha universidade.

Como eu gosto de relacionar a teoria com a prática, procurei intervir na Associação de Professores de História para que estas ideias e estes trabalhos fossem mais divulgados para lá da Universidade do Minho, que fica no extremo norte de Portugal. Lisboa fica no centro e com sua Associação de Professores acolhe professores de todo país. Através dessa associação, fui ganhando algumas pessoas que agora fazem também pós-graduação formação contínua com base nessas propostas no centro do 
país (incluindo a área de Lisboa). Há também algumas pessoas no sul do país, mas não tanto. Em relação ao centro do país, tivemos a sorte de, no departamento de história da Universidade de Coimbra, os nossos colegas também se mostrarem receptivos em discutir conosco as questões da educação histórica. Portanto, este movimento tem sido crescente, e uma vez que trabalhamos com a Associação de professores de história ele repercutiu-se até as estruturas políticas e, assim, temos contribuído também para políticas de ensino em Portugal.

Nucia Oliveira: Este ponto nos interessa bastante. Afinal, como foi a acolhida a ideia da Educação Histórica em Portugal?

Isabel Barca: Já a própria designação Educação Histórica foi muito bem acolhida e inclusive quando eu comecei a trabalhar com a Associação de Professores de História, o presidente resolveu fazer um congresso anual já com esse título "Educação Histórica em debate" . Nesse congresso, intervieram colegas nossos de várias universidades (colegas que participam na política educativa, colegas que são autores de manuais) e foi um diálogo muito interessante. A ideia de Educação Histórica quase foi universalmente acolhida. E, portanto, ficou. A ideia de Educação Histórica ficou.

Claro que depois o "praticar a Educação Histórica" foi mais difícil de interiorizar... Só aqueles sujeitos que estão a trabalhar conosco é que percebem que não estamos falando de opiniões de alunos quando dizemos que devemos ouvir os alunos. Não é perguntar "o que vocês acham da história?" . Não é isso. Queremos que eles falem de história e, a partir daí, nós analisaremos o seu pensamento histórico, a sua conceitualização da história. Isso é mais difícil. Quando começamos, por exemplo, a falar de narrativa houve também algumas más interpretações. Porque a ideia de narrativa era a narrativa do historiador ou a narrativa do professor. Inicialmente, era difícil perceber que nós falávamos da narrativa histórica não apenas como narrativa do historiador - e que, aliás, não é uma narrativa única já que existem divergências historiográficas. Isso era novo em termos de conceitualização em Portugal. O que nos interessava, sobretudo era perceber a narrativa que o aluno desenvolvia e isso era também muito novo. Por isso, estrategicamente, eu até durante alguns anos não falava em narrativa e nos congressos maiores do país - da Associação de professores de História - interrogavamme: "E então, a narrativa?" E eu fugia um pouco a questão porque não queria que a narrativa com a qual lidasse fosse mal entendida nesse sentido da narrativa do professor, que era a que imperava no momento. Só quando a ideia de que "os alunos pensam" e de que epistemologicamente existem várias narrativas historiográficas começou a ser interiorizada, só a partir daí, eu passei a colocar na agenda de investigação os estudos sobre narrativa. 
Nucia Oliveira: Por que esse elemento - a narrativa - é tão importante para a Educação Histórica?

A narrativa assume uma importância central na Educação Histórica porque ela, enquanto relato estruturado (descritivo e explicativo), é a forma usual de exprimir as ideias históricas, quer por historiadores, quer pelos audiovisuais, quer pelos professores e manuais. Como diz o filósofo Rüsen, a narrativa é a face da História. Portanto, para serem historicamente competentes também os alunos deverão comunicar as suas ideias em narrativa.

Nucia Oliveira: A senhora pode nos falar um pouco sobre a importância de trabalhar com as ideias substantivas... Qual o impacto que esse trabalho exerce no ensino de história?

Isabel Barca: Essa vertente de nosso trabalho é a que tem tido mais impacto entre os professores que não têm formação epistemológica ou uma formação mais avançada. Porque, na realidade, aquilo com que os professores lidam na sala de aula e aquilo que os pais pretendem é que os alunos saibam história substantiva. E foi precisamente por isso que nós começamos estes movimentos com a exploração de ideias substantivas em sala de aula, mas dentro do paradigma construtivista que era totalmente novo em Portugal - embora já se falasse nele ninguém o praticava. Essa vertente de trabalhar com os conceitos substantivos é para nós o primeiro passo, mas é um passo muito importante para ganhar os professores e também para ganhar os alunos desses professores que, ao trabalharem naquele formato de aula-oficina com os conteúdos, sentem-se mais incluídos na aula e sentem que as suas ideias também contam. A partir daí, os professores entusiasmando-se com essas questões por verem os alunos entusiasmados encontram uma espécie de arma para controlar a eficácia de seu trabalho. Com essa monitorização do ensino (fazendo o levantamento de ideais iniciais e depois fazendo o levantamento das ideias finais dos alunos) os professores ganham satisfação com o seu trabalho, novas indagações e vontade de saber mais.

Partindo dessas primeiras experiências, os professores podem avançar para indagações no plano das questões epistemológicas. Na parte curricular dos mestrados, os professores que vêm aos nossos cursos (e em Portugal são os professores que pagam a sua formação) desenvolvem, sobretudo, aulas oficinas com os seus alunos para explorar conceitos substantivos. Eles vão também tendo formação sobre questões de caráter epistemológico e, portanto, quando chega a hora de escolher o tema de sua dissertação, eles escolhem investigar ideias dos alunos a partir de conceitos históricos 
substantivos, obviamente, mas focando conceitos "de segunda ordem" que eles implicitamente revelam - ideias de mudança, de explicação, ideias de diversidade, diversidade de explicações, de versões, etc.

Nucia Oliveira: A área de ensino de história em Portugal como área de pesquisa é uma área consolidada? Qual o espaço que a Educação histórica tem nos curso de pósgraduação?

Isabel Barca: É uma área consolidada, certamente. Temos pesquisadores que estão fundamentalmente ligados à Universidade do Minho, mas isso não significa que todos os pesquisadores sejam dessa região. Aqui no evento (Jornadas de Educação Histórica) temos duas doutorandas que são de Lisboa, temos a Olga Magalhães que é da Universidade de Évora (que fica no sul de Portugal), a linha tem tido influência, têm circulado as ideias pelo país, mas daí... A passar à prática da maioria dos professores... Não podemos afirmar que haja um sucesso total, mas também não queremos uma hegemonia.

Nucia Oliveira: Pensando sobre as contribuições da Educação Histórica. Esse entusiasmo que a senhora mencionou, assim com a vontade de fazer algo significativo e de mostrar que as ideias dos alunos e dos professores fazem diferença talvez sejam as grandes contribuições da Educação Histórica. É isso mesmo?

Isabel Barca: Sim. Aliás, nós falamos no perfil de professor-investigador, em especial o "professor investigador social" , isto porque estamos na história - em que "investigador" pode ter o sentido de investigar história; eles podem investigar história, claro que também é necessário os professores investigarem os conteúdos de história que vão trabalhar dentro desta abordagem, mas isso não basta. É necessário que olhem as ideias de seus alunos e, portanto, esta ideia de professor investigador é muito interessante para o professor.

Nucia Oliveira: Em uma das mesas redondas realizadas durante o "XII Congresso Internacional Jornadas de Educação Histórica" a senhora falou sobre a construção de Diretrizes para o ensino de História em Portugal. Como tem sido esse processo? A educação histórica tem sido um referencial para essas discussões?

Isabel Barca: Houve já a produção de um documento em 2001 no plano do Ensino da História que já foi bastante influenciado pela nossa linha. Eu própria escrevi nesse documento uma parte, mas não quero dizer que tenha sido feito totalmente por 
nós. Já em 2010 e 2011, quando veio a proposta de se aprofundar as diretrizes políticas em termos de educação e construirmos um documento sobre as metas de aprendizagens das disciplinas,tive um convite direto para eu fazer uma equipe e escrevermos as metas de aprendizagem em história. Claro que se esse trabalho tivesse continuado, neste momento estaríamos na fase de experimentação desta proposta em várias escolas, com a implementação das estratégias que foram apresentadas no documento online. $E$ também de outras estratégias que nós construímos, com exemplos que acompanhavam as propostas de construir as aulas, e que não integraram o documento final. Face ao período de testagem, poderíamos eventualmente avançar para alguma reformulação dessas propostas... Como o governo caiu e iniciamos agora um novo governo dentro dessa linha de austeridade e de desenvolvimento econômico (mas de anti-desenvolvimento social, em que as áreas mais atacadas são as áreas de saúde, de educação e também de justiça) tememos um pouco pelo caminho que isto possa levar, na medida em que muitos professores ficarão desempregados, sobretudo os mais jovens... e quando eu digo os mais jovens não são os mais jovens de 20 anos mas sim os mais jovens entre 20 e 40 anos, que são normalmente os professores que vêm aos nossos mestrados e à nossa pós-graduação, e que têm competências mais avançadas para colocar a Educação Histórica dentro desses parâmetros. Esse aspecto vai dificultar o nosso trabalho. No entanto, temos uma rede já instituída e, portanto, acreditamos que algo se possa continuar a fazer neste trabalho porque pelo menos uma coisa ainda não desapareceu que é a liberdade de expressão e de pensamento. Em termos de política educativa, não temos neste momento expectativas muito positivas, mas pelo menos temos preservada a história no currículo - o que é muito bom. Aí, a própria opinião pública nos ajudou a expressar a ideia de que a história é importante no currículo de formação de nossos jovens.

Nucia Oliveira: A senhora demonstra grande preocupação com a situação profissional dos professores diante das questões políticas em Portugal. Além dessa situação - de fato muito alarmante - como formadora de professores quais são suas maiores preocupações? Quando a senhora ministra cursos para professores que questões costumam tratar?

Isabel Barca: Em termos científicos, procuro alargar os horizontes dos meus alunos no plano educacional e no plano epistemológico. Em relação ao primeiro destes planos, tento desafiar as ideias prévias, muito comuns em Portugal, de confundir construção do conhecimento com ensino acompanhado de simples atividades dos alunos sem um envolvimento autêntico na problematização e reconstrução conceptual. Para isso, proponho o desenho, a implementação e a análise de experiências em sala de 
aula que concretizem os princípios teóricos (a "aula oficina" ), e que eu acompanho como orientadora, dentro da postura de professor investigador social, parceira dos alunos co-investigadores. Em relação ao segundo plano, o de alargar os horizontes epistemológicos no âmbito das disciplinas de referência - a história em particular proponho a reflexão sobre a natureza da ciência, dos seus conceitos-chave e métodos, como suporte teórico das propostas de aula que vão sendo desenhadas, implementadas e analisadas. Duas vertentes epistemológicas têm sido objeto de atenção especial: a interpretação de fontes à maneira do (bom) historiador e a compreensão do mundo para uma orientação temporal - isto é, a formação de uma consciência histórica para o nosso tempo, quer por parte dos jovens alunos quer por parte de todos nós, formadores.

Nucia Oliveira: Ainda no que diz respeito à pesquisa, na opinião da senhora, quais os temas/campos de pesquisa sobre ensino de história precisam ser melhor aprofundados?

Isabel Barca: As questões da interpretação avançada de fontes - nas suas subtilezas de mensagens, na sua variedade de perspectivas, na sua diversidade de linguagens - são inesgotáveis. Atualmente, as questões sobre o conceito de mudança em História exigem também uma análise especial, para que os jovens não caiam em perigosos lugares comuns de que a História é simplesmente feita ou de ciclos, ou de progresso linear contínuo. E, claro, a ideia de construção de uma consciência histórica humanista, que ultrapasse e saiba combater os interesses de grupos particulares que se alimentam da miséria da maioria, continua - talvez continue sempre, no ensino da história e em todas as ciências sociais -como objeto de pesquisa diagnóstica e prognóstica.

Nucia Oliveira: Para finalizar, professora nos fale um pouco sobre as suas atuais pesquisas.

Isabel Barca: Eu acabei um projeto financiado por uma instituição nacional ligado ao Ministério da ciência e do ensino superior, que era o Projeto "Consciência Histórica - teorias e práticas" . Rüsen trouxe a ideia de consciência histórica ligada à necessidade de orientação temporal e de relacionar a história com a vida prática, o que é um desafio muito importante. O projeto que coordenei desenvolveu-se em duas fases e durou de 2003 até 2011. Aí passamos a explorar questões ligadas a narrativas, pois, como Rüsen diz, a narrativa é a face da consciência histórica, e pelas narrativas que os alunos constroem - narrativas livres - nós podemos ver como elas estão permeadas pela 
história, até que ponto é que elas mostram ligação da história com a vida dos seus autores, com suas preocupações enquanto sujeito e enquanto ser social. Esses aspectos foram muito enriquecedores para o nosso trabalho e, assim, já temos muitas publicações sobre narrativas históricas dos jovens. Agora tenciono fugir um pouco dessa ideia da narrativa e avançar para outra questão que é muito atual, a questão de ideia de mudança. Ela é importante para nos situarmos no momento de mudança drástica em Portugal - nós passamos de uma ideia de que estávamos a viver bem, que tínhamos conquistado muito em termos sociais a partir da revolução democrática (em 1974) e, agora de repente, somos confrontados com uma austeridade brutal e com uma necessidade de olharmos para uma sociedade que está a perder direitos sociais, que está a perder de fato direito a uma saúde de qualidade, a uma educação de qualidade para todos. Isto faz mexer muito com as pessoas e faz mexer muito com os alunos - as produções narrativas já mostram isso e, portanto, eu vou continuar com narrativas, mas acentuando o olhar sobre as ideias dos alunos acerca da mudança. Mas não chegará isso - porque isso é apenas um diagnóstico. Estamos agora a montar um conjunto de instrumentos para trabalharmos com os alunos e problematizarmos as ideias de mudança. Não podemos deixar que essa ideia de mudança seja conceitualizada de forma simplista como dizer que a história é apenas um ciclo... Tivemos um ciclo de prosperidade, agora temos um ciclo de austeridade e de recessão, mas tendendo a cristalizar-se em ideias do senso comum de que esse ciclo de recessão e de antidesenvolvimento social tornar-se-á, digamos, "ad eternum", como que não seja possível que a história mude num outro sentido. E, portanto, a compreensão dessa complexidade do conceito de mudança é necessária para se entender como a história é importante para a orientação na vida prática do ser humano. É isso que nesse momento estamos a fazer: construir novos materiais para questionarmos as ideias de mudança com os professores que vêm as nossas formações e que, por sua vez, irão fazer os questionamentos com nossos alunos. Por outro lado, continuar com a questão da narrativa, mas olhando, como já referi, sobretudo a forma como está sendo conceituada a ideia de mudança, e não colocando de parte a questão de interpretação avançada de fonte. Isto é também essencial numa sociedade global em que cada um expressa as suas ideias, e em sempre a expressão veicula as ideias que esse sujeito pensa, mas sim aquelas que são necessárias para enganar a maioria dos sujeitos. Portanto, as pessoas, os jovens, têm que ter armas para problematizar as várias informações que lhes chegam, inclusive através de vários meios de comunicação. 